\title{
Drone-Borne P-band Single-Pass InSAR
}

\author{
Laila Moreira $^{1}$, Dieter Lübeck ${ }^{4}$, Christian Wimmer $^{4}$, Felicio Castro ${ }^{1}$, Juliana A. Góes ${ }^{1}$, Valquiria Castro ${ }^{1}$, Marlon Alcântara ${ }^{1}$, \\ Gian Oré ${ }^{1}$, Luciano P. Oliveira ${ }^{1}$, Leonardo Bins ${ }^{2}$, Bárbara Teruel ${ }^{3}$, Lucas H. Gabrielli ${ }^{1}$, Hugo E. Hernandez-Figueroa ${ }^{1}$ \\ ${ }^{1}$ School of Electrical and Computer Engineering, University of Campinas - UNICAMP, Campinas, Brazil \\ ${ }^{2}$ National Institute for Space Research - INPE, São José dos Campos, Brazil \\ ${ }^{3}$ School of Agricultural Engineering, University of Campinas - UNICAMP, Campinas, Brazil \\ ${ }^{4}$ Radaz Ltda., São José dos Campos, Brazil \\ Email: luciano@decom.fee.unicamp.br
}

\begin{abstract}
This paper presents a high-accuracy single-pass drone-borne Interferometric Synthetic Aperture Radar System in the P-band (P-InSAR) for forest inventory, where ground and canopy heights are accurately determined. Full penetration is proven for a eucalyptus forest with a tree spacing of $2.5 \mathrm{~m}$ by 3.0 $\mathbf{m}$, and the measured digital terrain accuracy is compared with well-known statistical models. Combining a C-band single-pass InSAR with P-InSAR, forest height is estimated with $5 \%$ accuracy for forest inventory. Both surface and digital ground models are presented and compared with ground truth measurements.
\end{abstract}

Keywords - Single-pass P-band interferometry, drone-borne synthetic aperture radar, digital terrain model, digital surface model, forest height, forest inventory

\section{INTRODUCTION}

Interferometry is a technique that, if applied to Synthetic Aperture Radar (SAR) systems, can provide digital elevation models (DEMs). It is achieved by using the coherent properties of electromagnetic radiation to compare two or more echo waves from the same region, displaced in the across-track direction, to avoid target ambiguity. Calculating the angular difference between these echoes makes it possible to account for the distortion due to topography and determine the topography characteristics [1].

There are few ways to capture this data; one of them is to perform multiple flights over the region at different times using the same system, which is called repeat-pass interferometry. Another method, called single-pass interferometry, is based on performing one flight with two antennas physically separated in the same platform. The latter has the advantage of being cheaper and less time consuming since it only requires a single flight to collect all the necessary data.

The most well-known interferometry SAR system was the spaceborne SRTM deployed with the space shuttle by NASA in 2000. It operated for eleven days to perform a hundred and seventy-six orbits to gather data to make its famous DEM [2]. Another important interferometry SAR system that provides a DEM is the DLR's TANDEM-X launched in 2010 [3]. It achieves a height resolution of $2 \mathrm{~m}$ operating in X-band in the single-pass mode. SRTM, TANDEM-X and others [4,5] have the disadvantage of being spaceborne, making the project more expensive and more dependent on satellite orbit, i.e., its trajectory can hardly be modified.

A single-pass airborne P-band interferometry SAR system was first presented by the "GeoSAR" system in 2000 [6]. The $\mathrm{P}$-band antenna was placed at the wingtips with a horizontal baseline (straight line distance between the antennas) of $20 \mathrm{~m}$ and a nominal flight altitude of about $10.000 \mathrm{~m}$ above the ground. Another single-pass airborne interferometry system, also operating in the P-band, is the EcoSAR developed by NASA in 2011 [7, 8], which uses a baseline of $25 \mathrm{~m}$ at two altitudes $(3 \mathrm{~km}$ and $5 \mathrm{~km})$ in standard and ping-pong modes. Airborne system operations are less expensive than spaceborne, but they are still pricey for small organizations since it requires an airplane, a licensed flight crew, and a flight plan authorization. Recently the drone platform has turned into a feasible option for SAR missions [9-12]. The drone-borne SAR system used in this work has multi-band capabilities, as detailed in [12]. Though P-band is especially suitable for DEM generation due to its ability to penetrate forest areas, as detailed in [13]. These waves can pass through trees and reach the ground more easily, allowing the creation of elevation maps that take only the terrain profile into account.

This paper presents a lightweight drone-borne single-pass P-band interferometric solution, capable of performing arbitrary flight trajectories. The equipment has much lower manufacturing and operation costs than the spaceborne and airborne systems. It also requires a smaller, less specialized team to operate and needs less preparation time for missions. These characteristics create the possibility of using InSAR to map smaller areas, meeting the needs of many organizations, without losing the high-resolution required to generate accurate elevation maps.

The paper is organized as follows: Chapter 2 presents the background; Chapter 3, main applications; Chapter 4, the concept and design; Chapter 5, the results; and Chapter 6, the conclusion.

\section{BACKGROUND}

The terrain elevation or ground height is one of the most important parameters when making a field inventory. In some cases, the heterogeneity in forest development is mainly influenced by the local topography (slope angle, aspect, or elevation), which causes changes in soil depth and constitution, water content, and soil drainage, thus affecting forest structure and composition [14].

The forest height is also related to soil and forest parameters, enabling the estimation of the biomass in different kinds of forests with biomass estimation models instead of destructive methods [15-17]. The spatial distribution of forest height allows determining the stage of forest development (stock volume) in a region. The detection of gaps in the canopy with horizontal height distribution provides forest growth models, degradation of the canopy, and the competitions among species of trees $[18,19]$.

\section{APPLICATIONS}

Eucalyptus is the most worldwide planted tree due to its rapid growth and wide adaptability in different soils and climatic conditions, covering a global area of about 20 million 
hectares [20,21]. In Brazil, of the 7.84 million hectares of forest plantation, $72 \%$ of the land is destined to Eucalyptus [19], which is frequently used to obtain cellulose and wood. In this application, the P-InSAR system is capable of monitoring low-density forests using horizontal polarization. However, if analyzing tropical forests is required, then it is necessary to work with a fully polarimetric P-band to obtain a full illumination swath penetration [13].

In addition to the P-band, the drone-borne SAR system also operates in the C-band, which grants an amount of forest information that is very useful for producing forest inventories. In particular, the following information is acquired in a short period and with high resolution when compared with airborne SAR system: DEM, Digital Surface Model (DSM), forest height, biomass, and Diameter at Breast Height (DBH) estimations. The proposed solution can be applied from low-density forests to crops such as sugar cane, corn, and coffee.

\section{CONCEPT AND DESIGN}

\section{A. Radar Sensor Description}

The developed drone-borne SAR system consists of a radar designed to be transported by a multi-rotor drone with $5-\mathrm{kg}$ payload capacity. The radar block diagram is presented in Fig. 1, and it is noteworthy the presence of a motion-sensing system (MSS) composed of a single-channel GNSS receiver and an inertial measurement unit (IMU) that provides data for motion compensation within the range-doppler processor. The MSS, combined with a GNSS ground station, allows differential GNSS processing. Table I presents the MSS specifications, while a detailed radar description can be found in [22].

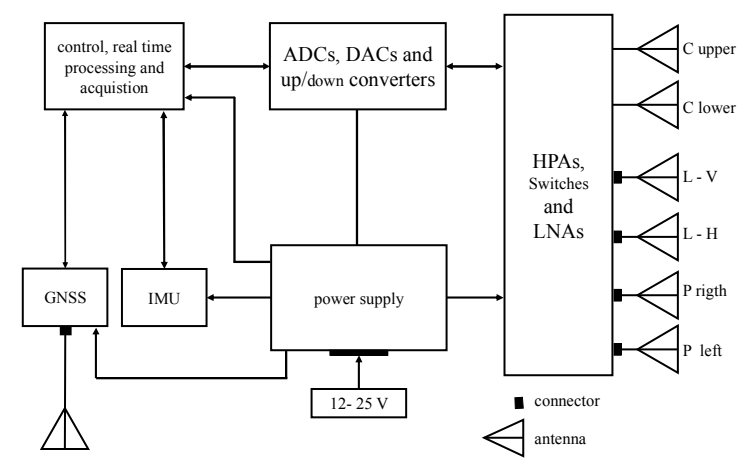

Fig. 1. Radar block diagram.

TABLE I. ACCURACY SPECIFICATIONS OF THE ADOPTED MOTION SENSING SYSTEM (MSS) [22].

\begin{tabular}{|l|c|}
\hline \multicolumn{1}{|c|}{ MSS Accuracy Specifications } & Value \\
\hline Position, Absolute & $0.015 \mathrm{~m}$ \\
\hline Position, Relative & $<0.01 \mathrm{~m}$ \\
\hline Roll and Pitch & $0.1^{\mathrm{o}}$ \\
\hline True Heading & $2^{\mathrm{o}}$ \\
\hline IMU Run Bias Stability & $2^{\mathrm{o}} / \mathrm{h}$ \\
\hline IMU Angular Random Walk & $0.1^{\mathrm{o}} / \mathrm{h}^{1 / 2}$ \\
\hline
\end{tabular}

Although the radar system is equipped with multi-band capabilities fully operational in the $\mathrm{P}, \mathrm{L}$, and C-bands, the Pband will be considered as the focus of this work. Simulations and measurements showed that the coupling between P-band antennas is about $-34 \mathrm{~dB}$, leading to an interferometric RMS phase error smaller than 0.06 degrees. Table II shows the main radar acquisition parameters at P-band. For a single-pass SAR interferometry, an antenna pair was mounted on the drone with a horizontal baseline, as showed in Fig. 2. Each of the eight-element-log-periodic dipole array aluminum antennas weighs $250 \mathrm{~g}$ and is $630-\mathrm{mm}$ long and $341-\mathrm{mm}$ wide. For design simplicity, this system version transmits only with one of the antennas and receives with both. This configuration suffers from a drawback of losing interferometric precision by a factor of 2 when compared to repeat-pass or single-pass ping-pong.

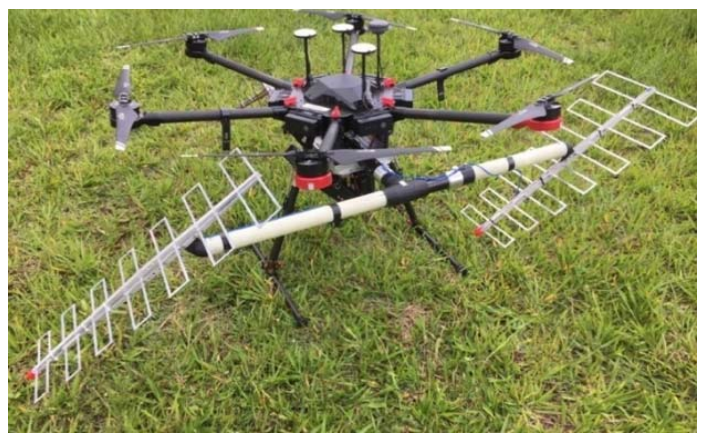

Fig. 2. P-band log-periodic antennas mounted on the drone.

TABLE II. MAIN RADAR ACQUISITION PARAMETERS AT P-BAND.

\begin{tabular}{|l|l|}
\hline \multicolumn{1}{|c|}{ Radar Parameters } & Value \\
\hline Carrier Wavelength & $68.92 \mathrm{~cm}$ \\
\hline Bandwidth & $50 \mathrm{MHz}$ \\
\hline Polarization & $\mathrm{HH}$ \\
\hline Peak Power & $100 \mathrm{~mW}$ \\
\hline Mean Power & $1 \mathrm{~mW}$ \\
\hline PRF & $10 \mathrm{kHz}$ \\
\hline Antenna Pointing Angle & $30^{\circ} \mathrm{below}$ horizon \\
\hline Incidence angle at swath start & $20^{\circ}$ \\
\hline Incidence angle at swath end & $70^{\circ}$ \\
\hline Incidence angle at swath center & $45^{\circ}$ \\
\hline Swath width & $290 \mathrm{~m}$ \\
\hline Mean Drone Height & $120 \mathrm{~m}$ \\
\hline Mean Drone Velocity & $7.5 \mathrm{~m} / \mathrm{s}$ \\
\hline Motion Sensing System (MSS) & D-GNSS+IMU \\
\hline Range Resolution & $3 \mathrm{~m}$ \\
\hline Azimuth Resolution & $0.5 \mathrm{~m}$ \\
\hline Processed Azimuth Bandwidth & $15 \mathrm{~Hz}$ \\
\hline Processed Aperture at 30 ${ }^{\circ}$ Incidence Angle & $100 \mathrm{~m}$ \\
\hline SLC Range Sampling & $0.61 \mathrm{~m}$ \\
\hline SLC Azimuth Sampling & $0.05 \mathrm{~m}$ \\
\hline
\end{tabular}

It is known that larger baselines give greater sensitivity to height variations [1]. Though, for the P-InSAR configuration, there are restrictions of size and weight that limit the length of the moving platform. In this case, the baseline length that can be achieved with the drone is $1.11 \mathrm{~m}$. 


\section{B. Radar Raw Data Processing Chain Description}

A standard interferometric processor was used to evaluate the P-band InSAR solution [22]. Fig. 3 presents the block diagram of its processing chain, which is carried out on the ground after the flight and can be explained as follows:

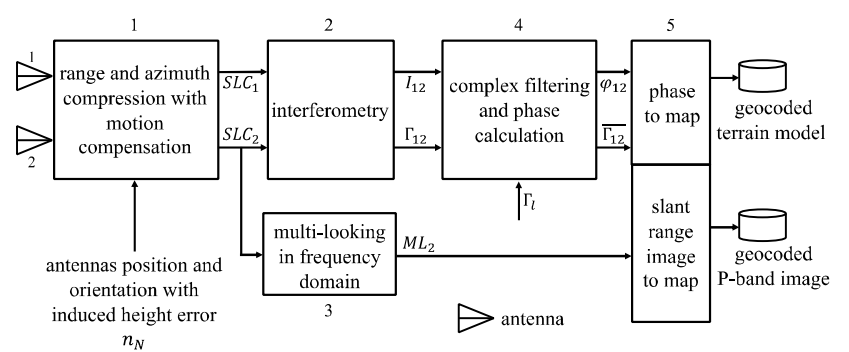

Fig. 3. Block diagram of the radar raw data processing chain.

1. The raw data from antennas 1 and 2 are first compressed in range and azimuth with motion compensation. The single-look-complex images, $S L C_{1}$ and $S L C_{2}$, are generated. The drone's position and orientation measurement errors induce a height error to the digital terrain model of $n_{\mathrm{N}}$. The main contribution comes from the roll angle error, which, multiplied by the range and projected from the local incidence angle to the vertical direction, causes the height error.

2. The interferometry of $S L C_{1}$ and $S L C_{2}$ is performed, and the complex interferogram $I_{12}$ and the coherence $\Gamma_{12}$ are calculated.

3. The Multi-look image of $S L C_{2}, M L_{2}$, is calculated. $S L C_{2}$ has no transmit-receive switch and has a higher $\mathrm{SNR}$ than $S L C_{1}$. For this reason, it was chosen for calculating $M L_{2}$.

4. $I_{12}$ is complex filtered considering the coherence threshold $\Gamma_{l}$, and the interferometric phase $\varphi_{12}$ is calculated. The corresponding filtered coherence $\underline{\Gamma}_{12}$ is also calculated.

5. $\varphi_{12}$ is converted to height and geocoded in the conversion process called "phase to map," generating the geocoded terrain model. Also, $M L_{2}$ is geocoded by using the same calculated height and within the same conversion process of the interferometric height.

\section{Interferometric Chain Design Steps}

The radar data processing chain was designed to fulfill the cartographic requirements for a scale of 1:50.000. The design steps, detailed in the following paragraphs, are (1) System requirements, (2) Resolution in slant range, (3) Resolution in azimuth, (4) Signal-to-noise ratio, and (5) Interferogram smooth filter size. Table IV presents each calculation step and its respective source.

\section{1) System requirements:}

The requirements are based on the map regulations of the "Ordinance Survey" and the "National Joint Utilities Group" of the United Kingdom. The main requirements are presented in Table IV, section 1.

\section{2) Resolution in slant range:}

The parameters in section 2 of Table IV are obtained from the requirements above and considering an average incidence angle of $45^{\circ}$.

\section{3) Resolution in azimuth:}

The azimuth beamwidth $\theta_{a}$ is $69.3^{\circ}$ [22] and results in a maximum achievable resolution of $\delta_{\text {amax }}=0.31 \mathrm{~m}$, as shown in Table IV, section 3. Considering the drone's stability in yaw, one gets a steady resolution in azimuth of $\delta_{a}=0.5 \mathrm{~m}$. Then, the resulting single-look-complex images $S L C_{1}$ and $S L C_{2}$ of Fig. 3 have a final resolution of $3 \mathrm{~m}$ in slant range and $0.5 \mathrm{~m}$ in azimuth. The multi-look image $M L_{2}$ has a final resolution of $3 \mathrm{~m}$ in slant range and $5 \mathrm{~m}$ in azimuth. The geocoded P-band image has a resolution of $5 \mathrm{~m}$ in both easting and northing directions.

\section{4) Signal-to-noise-ratio:}

The noise equivalent sigma zero (NESZ) of each P-band channel is $-27.3 \mathrm{~dB}$. Reflectivity is calculated from soil moisture measurements of the P-band image. This process needs a calibration step that uses soil samples analyzed by the gravimetric method [23]. The relation between the P-band reflectivity $\sigma_{0}$ and the soil moisture $m v$ can be expressed as:

$$
\sigma_{0}=0.42 m v-30.27 \text {. }
$$

Then, the signal to noise ratio (SNR) is acquired by subtracting the NESZ from $\sigma_{0}$. Assuming $m v=13 \%$, one gets an SNR of $2.3 \mathrm{~dB}$, as shown in Table IV, section 4 .

\section{5) Size of the interferogram smoothing filter:}

The final height accuracy $H_{a}$ is $3.33 \mathrm{~m}$ and can be expressed by the equation below [22]:

$$
H_{a}=\sqrt{n_{R}^{2}+n_{N}^{2}}
$$

where $n_{N}$ is the height error induced by the navigation system, and $n_{R}$ is the height error induced by the radar. The main source of $n_{N}$ is the roll angle error of the navigation system, and can be expressed as:

$$
n_{N} \approx \varepsilon_{\text {roll }} \cdot r_{\max }
$$

where $\varepsilon_{\text {roll }}$ is the roll angle error and $r_{\max }$ is the maximum range. $r_{\max }$ is $312 \mathrm{~m}$ and, form Table $\mathrm{I}, \varepsilon_{\text {roll }}$ is $0.1^{\circ}$ or 0.0017 rad; thus, the resulting $n_{N}$ is $0.54 \mathrm{~m}$, as shown in Table IV, section 5. Considering (2), the height error induced by the radar $n_{R}$ should be equal to or smaller than $3.3 \mathrm{~m}$ for fulfilling the final height accuracy of $3.33 \mathrm{~m}$. Therefore, the smoothing filter size will be calculated for guaranteeing the required $n_{R}$. The relationships between the SNR, the standard deviation of the phase noise $\delta_{\varphi 1}$, and the coherence $\Gamma_{12}$ are presented in Table III [24]. An SNR of $2.3 \mathrm{~dB}$ produces $\delta_{\varphi 1}=70^{\circ}$ and an estimated coherence $\Gamma_{12}=0.6$.

TABLE III. COHERENCE AND PHASE NOISE DEPENDENT ON SNR [24].

\begin{tabular}{|c|c|c|}
\hline SNR [dB] & Coherence & Phase Noise $\left[^{\circ}\right]$ \\
\hline 2.3 & 0.6 & 70 \\
\hline 6.5 & 0.8 & 52 \\
\hline 10.0 & 0.9 & 38 \\
\hline
\end{tabular}

The phase noise $\delta_{\varphi 1}$ contributes to the standard deviation $\delta_{n 1}$ of the height error induced by the radar according to the following expression: 


$$
\delta_{n 1}=\frac{\lambda r}{2 \pi B \cos \left(\theta_{i}\right)} \delta_{\varphi 1}
$$

where $r$ is the range at the middle of the swath, equal to 120 $\mathrm{m} ; B$ is the horizontal baseline of the P-band antennas, equal to $1.11 \mathrm{~m}$; and $\theta_{i}$ is the incidence angle in the middle of the swath, equal to $45^{\circ}$. The resulting $\delta_{n}$ is $29.4 \mathrm{~m}$, as shown in Table IV, section 5 , and must be reduced nine times for attaining $n_{R}<3.3 \mathrm{~m}$. This reduction can be achieved by applying a $2 \mathrm{D}$ complex filter to the interferogram $I_{12}$, as shown in Fig.3. The relationship between $n_{R}$ and $\delta_{n 1}$ is:

$$
n_{R}=\frac{\delta_{n 1}}{\sqrt{F_{a} \cdot F_{r}}}
$$

where $F_{a}$ and $F_{r}$ are the complex filter box sizes in azimuth and range, respectively. $F_{a}$ and $F_{r}$ represent the number of resolution cells that are statistically independent of their neighbors. A compromise was found using $F_{a}=24$ and $F_{r}=$ 4, ensuring $n_{R}=3 \mathrm{~m}$ and $H_{a}=3.05 \mathrm{~m}$, as shown in Table IV, section 5 , but with a resolution of $12 \mathrm{~m}$ in both slant range and azimuth directions. Considering a $31 \%$ soil moisture or a distributed target with reflectivity of $-17 \mathrm{~dB}$, the SNR becomes $10 \mathrm{~dB}$, the coherence turns into 0.9 , and $H_{a}$ is improved to $1.7 \mathrm{~m}$.

\section{RESULTS}

An area of about $1 \mathrm{~km}^{2}$, mainly covered by a eucalyptus forest with $19 \mathrm{~m}$ canopy height, was surveyed by 6 flight lines with a $50 \%$ overlap. Three corner reflectors were placed for resolution verification and planimetric accuracy.

The drone presented an orientation error of less than $2^{\circ}$ RMS and a position error of less than $0.3 \mathrm{~m}$ RMS. The accuracy of the navigation system is shown in Table I. Fig. 4 presents the optical image from Google Maps. The forest is located in the middle of the image. Fig. 5 shows the C-band image overlaid on the optical image and Fig. 6, the corresponding P-band image. The red segment in Fig. 5 indicates the line were the height measurements were carried out.

The digital surface model derived from the C-band interferometry is shown in Fig. 7: darker means lower and brighter means higher. The height transition at the border of the forest can be clearly seen. Fig. 8 presents the digital terrain model from the P-band interferometry: no height transition can be observed at the border of the forest. The P-band penetration capability is displayed in Fig. 9, where both $\mathrm{P}$ and $\mathrm{C}$-band height profiles are shown. The C-band DSM has a 3 meters smooth size and the P-band DTM has a 12 meters smooth size. The P-band height profile shows a slope of $5 \mathrm{~m}$ in the forested area due to a valley in the west direction. However, the forest height does not follow this slope due to the increasing gradient of the soil moisture in the valley direction and the dispute of trees for sunlight. The C-band height profile shows an altitude of $669 \mathrm{~m}$ in the forest area and the same altitude as the P-band height profile in the neighboring open field. If the $\mathrm{C}$-band height profile is subtracted from the P-band one, a mean forest height of $19 \mathrm{~m}$ is obtained.

Fig. 10 shows the histogram of the P-band coherence. Most of the values are between 0.75 and 0.91 , showing an
SNR predominance between 5 and $15 \mathrm{~dB}$, respectively, as seen in Table III.

\begin{tabular}{|c|c|}
\hline Parameters & Value \\
\hline \multicolumn{2}{|l|}{ 1. Requirements } \\
\hline Height accuracy & $3.33 \mathrm{~m}$ \\
\hline Planimetric accuracy & $8.51 \mathrm{~m}$ \\
\hline Image resolution & $5 \mathrm{~m}$ \\
\hline Soil: flat, vegetation-free, moisture & $13 \%$ \\
\hline \multicolumn{2}{|l|}{ 2. Resolution in range } \\
\hline Slant range bandwidth & $50 \mathrm{MHz}$ \\
\hline Slant range resolution & $3 \mathrm{~m}$ \\
\hline Ground range resolution & $4.2 \mathrm{~m}<5 \mathrm{~m}$ \\
\hline \multicolumn{2}{|l|}{ 3. Resolution in azimuth } \\
\hline Azimuth beamwidth $\left(\theta_{a}\right)$ & $69.3^{\circ}$ \\
\hline Antenna aperture & $0.62 \mathrm{~m}$ \\
\hline Maximum azimuth resolution $\left(\delta_{a \max }\right)$ & $0.31 \mathrm{~m}$ \\
\hline Azimuth resolution $\left(\delta_{a}\right)$ & $0.5 \mathrm{~m}$ \\
\hline \multicolumn{2}{|l|}{ 4. Signal to noise ratio } \\
\hline NESZ & $-27.3 \mathrm{~dB}$ \\
\hline Reflectivity $\left(\sigma_{0}\right)$ & $-25 \mathrm{~dB}$ \\
\hline SNR & $2.3 \mathrm{~dB}$ \\
\hline \multicolumn{2}{|c|}{ 5. Size of the interferogram smoothing filter } \\
\hline Roll angle error $\left(\varepsilon_{\text {roll }}\right)$ & $0.1^{\circ}$ \\
\hline Height error induced by the navigation system $\left(n_{N}\right)$ & $0.54 \mathrm{~m}$ \\
\hline Height error induced by the radar $\left(n_{R}\right)$ & $3 \mathrm{~m}$ \\
\hline Standard deviation of $n_{R}\left(\delta_{n 1}\right)$ & $29.4 \mathrm{~m}$ \\
\hline Final height accuracy $\left(H_{a}\right)$ & $3,05 \mathrm{~m}$ \\
\hline Phase noise $\left(\delta_{\varphi 1}\right)$ & $70^{\circ}$ \\
\hline Coherence $\left(\Gamma_{12}\right)$ & 0.6 \\
\hline Complex filter box size in azimuth $\left(F_{a}\right)$ & 24 \\
\hline Complex filter box size in range $\left(F_{r}\right)$ & 4 \\
\hline
\end{tabular}

TABLE IV. INTERFEROMETRIC CHAIN DESIGN STEPS.

The P-band height accuracy was determined by measuring the height RMS error between overlapping areas every two neighboring tracks and also by field survey. The P-band height accuracy is estimated about $1.5 \mathrm{~m}$ for the forest area and 2.5 $\mathrm{m}$ for the open field area, with soil moisture close to $15 \%$. The resolution of the P-band image was measured using three corner reflectors and it is equal to $5 \mathrm{~m}$ in both the North and East directions.

The planimetric accuracies of the $\mathrm{C}$ - and P-band images were verified and are better than $2 \mathrm{~m}$. Comparing the forest height information with the forest inventory of the fieldwork, one gets an accuracy better than $5 \%$ by integrating areas with dimensions of $50 \mathrm{~m} \times 50 \mathrm{~m}$. The accuracy is incidence-angle independent and shows the full penetration capability of the $\mathrm{HH}$-polarized P-band wave for a eucalyptus forest with $3 \mathrm{~m} \mathrm{x}$ $2.5 \mathrm{~m}$ spacing. 


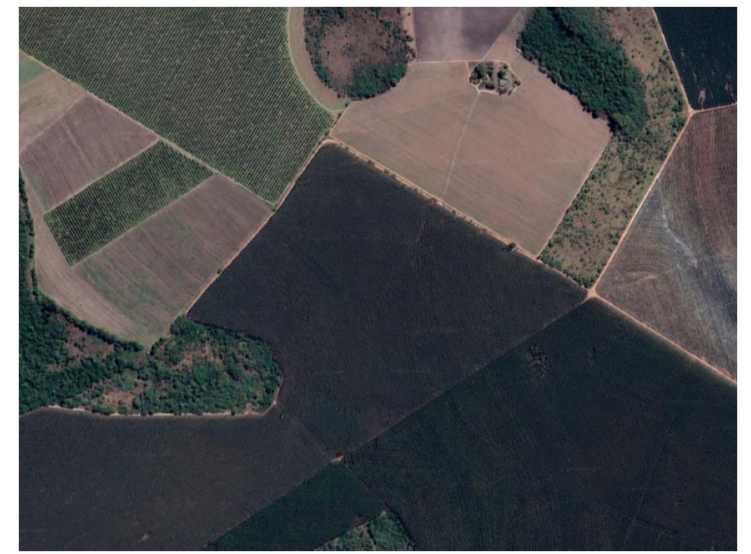

Fig. 4. Optical image of the test area.

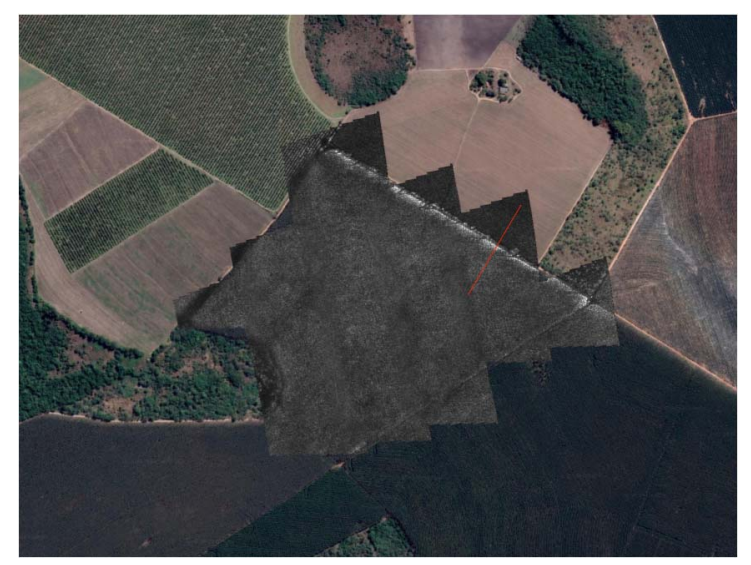

Fig. 5. C-band image overlaid on the optical one.

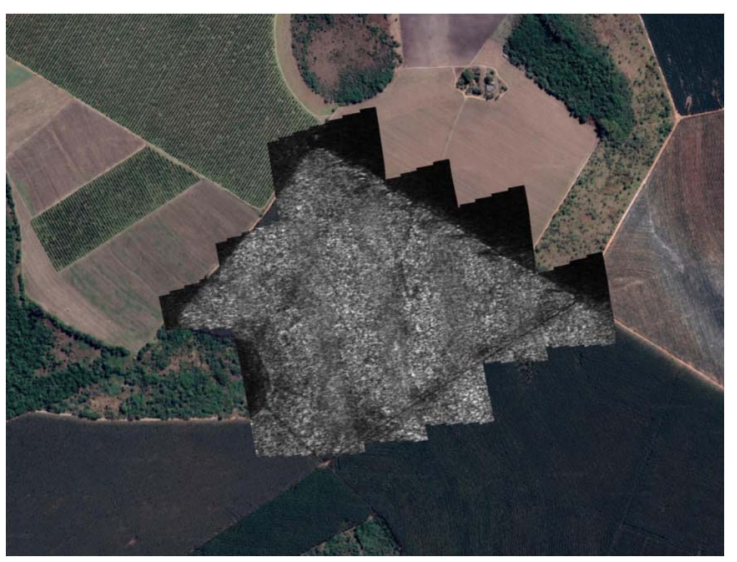

Fig. 6. P-band image overlaid on the optical one.

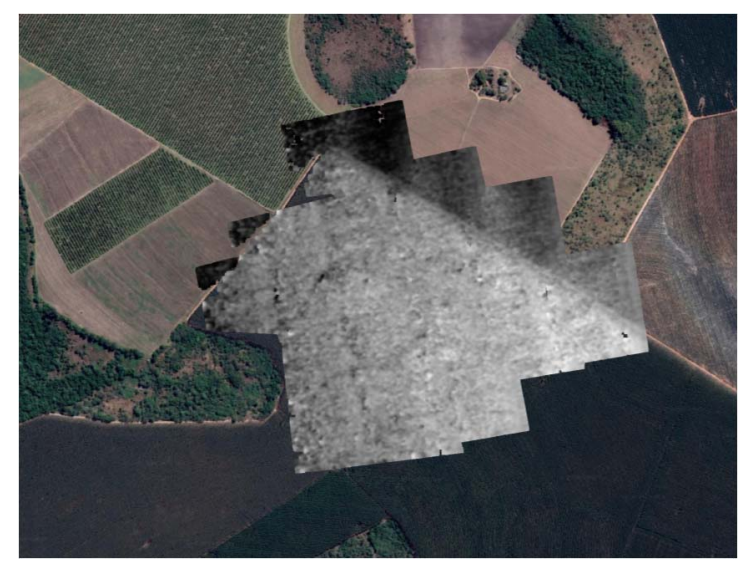

Fig. 7. Digital Surface Model from C-band InSAR.

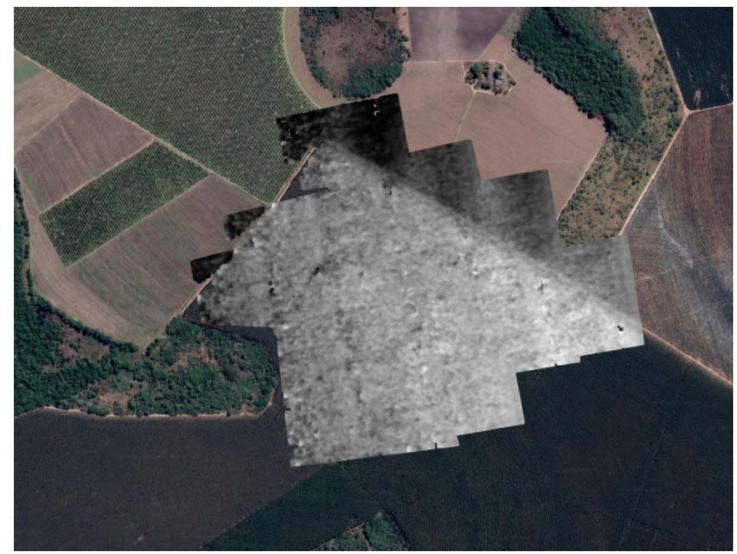

Fig. 8. Digital Surface Model from C-band InSAR.

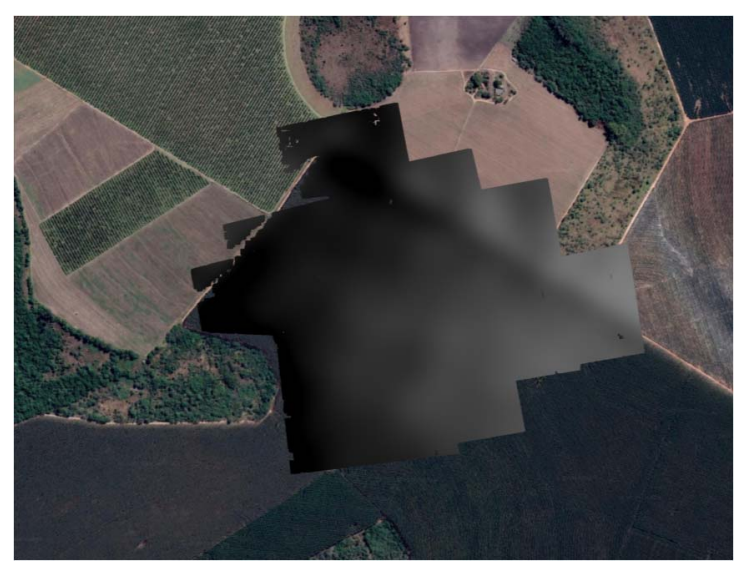

Fig. 9. Digital Terrain Model from P-band InSAR.

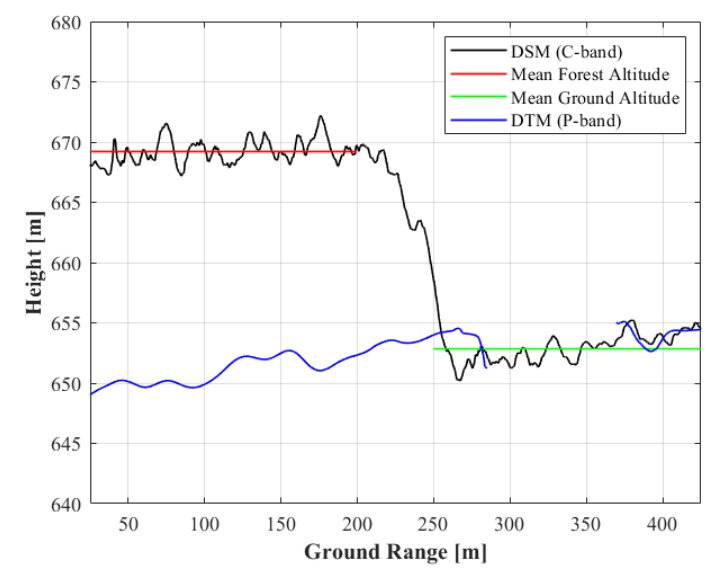

Fig. 10. The height profile of the forest and neighboring open areas.

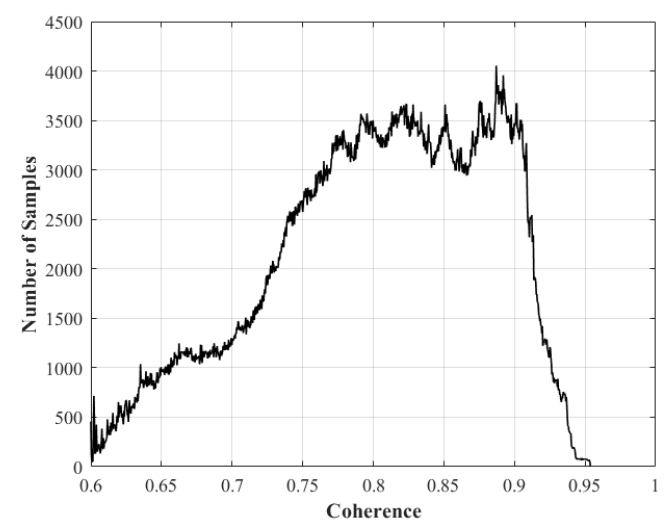

Fig. 11. Coherence histogram from P-band InSAR. 


\section{CONCLUSIONS}

The drone-borne P-band InSAR system presented in this paper allows the estimation of the terrain height of a eucalyptus forest with an accuracy better than $1 \mathrm{~m}$ or $5 \%$. It is possible thanks to the forest SNR being higher than $17 \mathrm{~dB}$ and the measurements being integrated over a $50 \mathrm{~m} \times 50 \mathrm{~m}$ area.

On vegetation-free areas with $15 \%$ soil moisture, the measured terrain height shows a height accuracy better than $3.3 \mathrm{~m}$. In both cases, their products, the image resolution, planimetric accuracy, and terrain model accuracy comply with the requirements of the cartography at a scale of 1:50.000. In addition, the combination of the $\mathrm{C}$ and $\mathrm{P}$-bands data shows an excellent tool for producing forest inventory.

The terrain height accuracy can be improved twice if the radar is upgraded with the single-pass ping-pong mode: each antenna transmits and receives. Volume decorrelation of the forest is present in the P-band interferogram. It is small enough not to degrade the HH-polarized P-band wave penetration capability in this type of forest. Its reflectivity is between $-10 \mathrm{~dB}$ and $0 \mathrm{~dB}$, which implies an SNR and coherence higher than $17 \mathrm{~dB}$ and 0.95 , respectively. Fig. 10 shows that the measured coherence is limited to 0.95 . In the case of the rainforest, the HH-polarized P-band wave penetration capability efficiency is limited to incidence angles lower than 50 degrees [13].

To the best of our knowledge, the drone-borne P-band single-pass interferometric SAR system presented here is novel and displays unparalleled accuracy and resolution.

\section{ACKNOWLEDGMENT}

The authors would like to thank the Brazilian government agencies CAPES and CNPq, and São Paulo Research Foundation (FAPESP) under the contracts PITE 2017/194163, PIPE 2018/00601-8, and grants: 2018/14690-2 and 2018/12726-0 for supporting this work and WZ for the forest survey and information.

\section{REFERENCES}

[1] I. H. Woodhouse, Introduction to microwave remote sensing. Speckled Press, 2015.

[2] Farr, Tom G., et al. "The shuttle radar topography mission." Reviews of geophysics, vol 45, n. 2, 2007.

[3] A. Moreira et al., "TanDEM-X: a terraSAR-X add-on satellite for single-pass SAR interferometry," in Proc. 2004 IEEE International Geoscience and Remote Sensing Symposium (IGARSS), Anchorage, AK, USA, 2004, vol. 2, pp. 1000-1003.

[4] F. K. Li and R. M. Goldstein, "Studies of multibaseline spaceborne interferometric synthetic aperture radars," IEEE Trans. Geosci. Remote Sensing, vol. 28, no. 1, pp. 88-97, January 1990.

[5] C. Prati, F. Rocca, and A. Monti Guarnieri, "SAR interferometry experiments with ERS-1," in Proc. First ERS-1 Symposium, Space at the Service of our Environment, Cannes, France, 1992, pp. 211-218.

[6] S. Hensley et al., "First P-band results using the GeoSAR mapping system," in Proc. IGARSS 2001. Scanning the Present and Resolving the Future. IEEE 2001 International Geoscience and Remote Sensing
Symposium (Cat. No.01CH37217), Sydney, NSW, Australia, 2001, vol. 1, pp. 126-128.

[7] R. F. Rincon et al., "The EcoSAR P-band Synthetic Aperture Radar," in Proc. 2011 IEEE International Geoscience and Remote Sensing Symposium (IGARSS), Vancouver, BC, 2011, pp. 1512-1515.

[8] R. F. Rincon et al., "ECOSAR: P-band digital beamforming polarimetric and single pass interferometric SAR," in Proc. 2015 IEEE Radar Conference (RadarCon), Arlington, VA, USA, 2015, pp. 06990703.

[9] C. J. Li and H. Ling, "Synthetic aperture radar imaging using a small consumer drone," in Proc. 2015 IEEE International Symposium on Antennas and Propagation \& USNC/URSI National Radio Science Meeting, Vancouver, BC, Canada, 2015, pp. 685-686.

[10] J. Yan, J. Guo, Q. Lu, K. Wang, and X. Liu, "X-band mini SAR radar on eight-rotor mini-UAV," in Proc. 2016 IEEE International Geoscience and Remote Sensing Symposium (IGARSS), Beijing, China, 2016, pp. 6702-6705.

[11] S. Dill, E. Schreiber, M. Engel, A. Heinzel, and M. Peichl, "A drone carried multichannel Synthetic Aperture Radar for advanced buried object detection," in Proc. 2019 IEEE Radar Conference (RadarConf), Boston, MA, USA, 2019, pp. 1-6.

[12] L. Moreira et al., "A Drone-borne Multiband DInSAR: Results and Applications," in Proc. 2019 IEEE Radar Conference (RadarConf), Boston, MA, USA, 2019, pp. 1-6.

[13] G. H. X. Shiroma, K. A. Camara de Macedo, C. Wimmer, J. R. Moreira, and D. Fernandes, "The Dual-Band PolInSAR Method for Forest Parametrization," IEEE Journal of Selected Topics in Applied Earth Observations and Remote Sensing, vol. 9, no. 7, pp. 3189-3201, July 2016.

[14] S. Ediriweera, T. Danaher, and S. Pathirana, "The influence of topographic variation on forest structure in two woody plant communities: A remote sensing approach," Forest Syst, vol. 25, no. 1, April 2016.

[15] A. N. Wassihun, Yousif A. Hussin, L. M. V. Leeuwen, and Z. A. Latif, "Effect of forest stand density on the estimation of above ground biomass/carbon stock using airborne and terrestrial LIDAR derived tree parameters in tropical rain forest, Malaysia," Environmental Systems Research, vol. 8, no. 1, August 2019.

[16] M. J. Ducey, D. J. Zarin, S. S. Vasconcelos, and M. M. Araújo, "Biomass equations for forest regrowth in the eastern Amazon using randomized branch sampling," Acta Amaz., vol. 39, no. 2, pp. 349-360, 2009.

[17] A. H. Youkhana, R. M. Ogoshi, J. R. Kiniry, M. N. Meki, M. H. Nakahata, and S. E. Crow, "Allometric Models for Predicting Aboveground Biomass and Carbon Stock of Tropical Perennial C4 Grasses in Hawaii," Front. Plant Sci., vol. 8, May 2017.

[18] F. Albert, "Pol-InSAR Forest Height estimation at different Frequencies: Opportunities and Limitations," $\mathrm{PhD}$, Technicsche Universität München, 2015.

[19] T. H. Booth, "Eucalypt plantations and climate change," Forest Ecology and Management, vol. 301, pp. 28-34, August 2013.

[20] “Report 2017," Brazilian Tree Industry (IBA), 2017. Accessed: March 23, 2020. [Online]. Available at: https://iba.org/images/shared/ Biblioteca/IBA_RelatorioAnual2017.pdf.

[21] N. F. Barros and N. Comerford, "Sustentabilidade da produção de florestas plantadas na região tropical," Tópicos em Ciência do Solo, vol. 2, pp. 487-592, 2002.

[22] D. Luebeck et al., "Drone-borne Differential SAR Interferometry," Remote Sensing, vol. 12, no. 5, February 2020.

[23] N. Baghdadi et al., "Operational Mapping of Soil Moisture Using Synthetic Aperture Radar Data: Application to the Touch Basin (France)," Sensors, vol. 7, pp. 2458-2483, 2007.

[24] Just and R. Bamler, "Phase statistics of interferograms with applications to synthetic aperture radar," Appl. Opt., vol. 33, no. 20, July 1994. 